Article

\title{
Differences in Metal Ions Released from Orthodontic Appliances in an In Vitro and In Vivo Setting
}

\author{
Vito Kovac ${ }^{1}$, Borut Poljsak ${ }^{2}\left(\mathbb{D}\right.$, Matic Bergant ${ }^{2}$, Janez Scancar ${ }^{2}\left(\mathbb{D}\right.$, Uros Mezeg $^{3}$ and Jasmina Primozic ${ }^{3, *(1)}$ \\ 1 Faculty of Health Sciences, University of Ljubljana, SI-1000 Ljubljana, Slovenia; vito.kovac@zf.uni-lj.si \\ 2 Department of Environmental Sciences, Jozef Stefan Institute, SI-1000 Ljubljana, Slovenia; \\ borut.poljsak@zf.uni-lj.si (B.P.); matic.bergant@ijs.si (M.B.); janez.scancar@ijs.si (J.S.) \\ 3 Faculty of Medicine, University of Ljubljana, SI-1000 Ljubljana, Slovenia; beli.medved@telemach.net \\ * Correspondence: jasminaprimozic@gmail.com
}

check for

updates

Citation: Kovac, V.; Poljsak, B.; Bergant, M.; Scancar, J.; Mezeg, U.; Primozic, J. Differences in Metal Ions Released from Orthodontic

Appliances in an In Vitro and In Vivo Setting. Coatings 2022, 12, 190.

https://doi.org/10.3390/

coatings 12020190

Academic Editor: Devis Bellucci

Received: 29 December 2021

Accepted: 28 January 2022

Published: 1 February 2022

Publisher's Note: MDPI stays neutral with regard to jurisdictional claims in published maps and institutional affiliations.

Copyright: (C) 2022 by the authors. Licensee MDPI, Basel, Switzerland. This article is an open access article distributed under the terms and conditions of the Creative Commons Attribution (CC BY) license (https:// creativecommons.org/licenses/by/ $4.0 /)$.

\begin{abstract}
The aim was to assess the composition of released metal ions from fixed orthodontic appliances both in an in vitro and in vivo setting and to compare their quantities to evaluate any possible health risks associated with them. For the in vitro setting, a set of 24 as-received sterile SS brackets, 2 SS sterile archwires, and 2 NiTi sterile archwires were aged for 90 days in artificial saliva, and released metal ion concentrations were determined by inductively coupled plasma mass spectrometry (ICP-MS), using matrix-matched standards for calibration. For the in vivo setting, 15 brackets, 15 SS, and $15 \mathrm{NiTi}$ archwires were retrieved after 90 days of intraoral exposure in 15 subjects. Debris composition on each part of the orthodontic appliance was assessed using scanning electron microscopy with energy dispersive spectroscopy (SEM/EDS). The present study evidenced a difference in the composition of released metal ions from fixed orthodontic appliances detected in an in vitro and in vivo setting. Generally, the relative content of metal ions was higher in the retrieved debris than that released in artificial saliva. The concentration of released metal ions from all tested alloys was below the upper recommended limit of daily intake; however, possible local effects in terms of hypersensitivity due to their accumulation in the debris cannot be excluded even with such concentrations.
\end{abstract}

Keywords: orthodontic appliances; fixed appliances; biocompatible materials

\section{Introduction}

Fixed orthodontic appliances are subjected for several months to the oral environment with ever-changing $\mathrm{pH}$ and temperature, as well as biological and enzymatical composition [1]. More in detail, brackets are seldomly changed over the whole treatment duration, which approximately lasts 24 months, while archwires are generally changed every 1-3 months of treatment. Moreover, brackets and archwires are subjected not only to electrochemical corrosion but also to mechanical friction during orthodontic treatment due to the constant sliding of the wires in the brackets' slots [2]. This may also influence surface degradation (tribocorrosion) and, therefore, increase metal ions' release. Stainless steel (SS) and nickel-titanium (NiTi) are the most commonly used alloys of which either brackets or archwires are made. The nickel (Ni) ion has been described as the most allergenic compound among orthodontic alloys [3], closely followed by chromium (Cr) [4-6]. Additionally, it has been evidenced that the most common metals in dental alloys (Ni, $\mathrm{Cr}$, $\mathrm{Co}, \mathrm{Fe}, \mathrm{Ti}$ ) may cause either systemic or local toxic or biological effects [7]. In particular, several pathologic oral tissues reactions have been reported during orthodontic treatment, including contact stomatitis, multiform erythema, and gingival hypertrophy, which might be related to the toxic effects of metal ions released from fixed orthodontic appliances $[8,9]$.

Although biocompatibility concerns due to intraoral corrosion and tribocorrosion of various types of alloys, including SS and NiTi, have arisen through the years, no consistent 
results regarding metal ion release and their toxic effects on oral tissues have been obtained yet. In fact, due to the constantly changing oral environment and saliva flow, it appears very difficult to prepare an in vitro setting that would enable studying the actual toxic load of released metal ions on oral tissues [10]. Because of the numerous factors that must be considered to reliably mimic intraoral conditions, such as extreme $\mathrm{pH}$ or temperature fluctuations, bracket-to-wire type of ligation and friction, and the presence of intraoral microbial flora and plaque accumulation, it appears challenging to conduct an in vitro experiment inclusive of all possible conditions of the oral cavity [11]. Furthermore, tribocorrosion is rarely, if at all, considered when testing the in vitro release of metal ions from dental alloys [12]. On the other hand, in vitro studies give valuable insight regarding metal ion release from orthodontic appliances due to their controlled and standardized conditions. To our best knowledge, there is a scarcity of studies aimed at comparing metal ion release from orthodontic appliances in an in vitro and in vivo setting.

Therefore, the aim of the present study was to assess the composition of released metal ions from fixed orthodontic appliances both in an in vitro and in vivo setting and to compare their quantities to evaluate any possible health risks associated with them. Due to the complex intraoral environment, a difference in the release and accumulation of metal ions was expected between the in vitro and in vivo setting.

\section{Materials and Methods}

\subsection{Assessment of the Metal Composition of Brackets and Archwires}

To determine the metal composition of samples, approximately $10 \mathrm{mg}$ of each sample was digested entirely in $5 \mathrm{~mL}$ of appropriate acid by heating the solution at $90^{\circ} \mathrm{C}$. Stainless steel samples (according to manufacturer declaration brackets and SS archwires) were digested in aqua regia, while the NiTi archwires (according to manufacturer declaration) were digested in a mixture of $\mathrm{HNO}_{3}, \mathrm{HF}$, and $\mathrm{HCl}$ (4:2:1 volume ratio). The digested samples' total metal ion concentrations were determined by inductively coupled plasma mass spectrometry (ICP-MS) on an Agilent 7700x ICP-MS instrument (Tokyo, Japan), using matrix-matched standards for calibration. The metal ion content of brackets, SS, and NiTi archwires was expressed as wt.\%.

\subsection{In Vitro Setting}

In the present study, a set of 24 as-received sterile SS brackets, 2 SS sterile archwires, and $2 \mathrm{NiTi}$ sterile archwires were aged for 90 days in artificial saliva, which was prepared using an aqueous solution of $\mathrm{NaCl}, \mathrm{KCl}, \mathrm{CaCl}_{2} \cdot 2 \mathrm{H}_{2} \mathrm{O}, \mathrm{NaH}_{2} \mathrm{PO}_{4} \cdot 2 \mathrm{H}_{2} \mathrm{O}, \mathrm{Na}_{2} \mathrm{~S} \cdot 9 \mathrm{H}_{2} \mathrm{O}$, and urea in concentrations $400 \mathrm{mg} / \mathrm{mL}, 400 \mathrm{mg} / \mathrm{mL}, 960 \mathrm{mg} / \mathrm{L}, 690 \mathrm{mg} / \mathrm{L}, 5 \mathrm{mg} / \mathrm{L}$, and $1000 \mathrm{mg} / \mathrm{L}$, respectively. All reagents were of high purity and purchased from Merck (Darmstadt, Germany). Ultrapure water (Milli-Q, $18.2 \mathrm{M} \Omega \cdot \mathrm{cm}$ ) obtained from a DirectQ 5 ultrapure water system (Millipore, Watertown, MA, USA) was used for the solution preparation. The medium was then adjusted to a $\mathrm{pH}$ of $6.7-6.8$, resembling neutral $\mathrm{pH}$ in the oral cavity. A WTW (Weilheim, Germany) $330 \mathrm{pH}$ meter was employed to determine the $\mathrm{pH}$. Teflon beakers were used to minimize blanks and prevent the absorption of metals on the walls of the containers during the experiment. An amount of $250 \mathrm{~mL}$ of artificial saliva was added to each beaker, along with the sample of parts of fixed orthodontic appliances (either the set of 24 brackets or two archwires (SS or NiTi). To control the blanks arising from the chemicals and the potential leaching of metal ions from the beakers used, $250 \mathrm{~mL}$ of artificial saliva was added into the Teflon beaker and analyzed along with the samples throughout the experiment. Blank values were subtracted from the determined concentrations of elements released from the submerged parts of fixed orthodontic appliances into artificial saliva. Samples were incubated in a dust-free incubator (Kambič, Semič, Slovenia) at $37^{\circ} \mathrm{C}$ for 90 days. Before the sampling procedure, each Teflon beaker was gently turned upside down two times to ensure the even distribution of elements in the sample volume. An amount of $3 \mathrm{~mL}$ of sample was taken from each beaker, acidified with $6 \mu \mathrm{L}$ of supra pure nitric acid, and stored at $-20{ }^{\circ} \mathrm{C}$ until the analysis. Total metal ion concentrations 
released in artificial saliva were determined by ICP-MS, using matrix-matched standards for calibration.

\subsection{Assessment of the Accuracy of the Determination of Metal Ions}

The accuracy of the verification of metal ions in the analyzed samples was assessed by the spike recovery test, as suggested in a previous study [13]. Briefly, bracket samples were spiked with known amounts of elements before the digestion process, and the analysis was performed. To evaluate the accuracy of the determination of the concentrations of metal ions released into artificial saliva, the samples collected after the 90 days incubation period were spiked with known amounts of metals, and concentrations were determined by ICP-MS. Good agreement was evidenced with differences between the theoretically calculated and measured concentrations of less than 5\%. Along with the investigated samples, blank samples of artificial saliva were analyzed as controls.

\subsection{In Vivo Setting}

For the in vivo part of the study, ethical approval (Ref. No 126/04/13) and written informed consent of the subjects included in the study were obtained. Fifteen healthy subjects ( 9 females, 6 males) aged $14.0 \pm 0.8$ years in whom treatment with fixed appliances was planned due to mild teeth crowding, were included. The subjects were instructed regarding oral hygiene protocol and were given a starting kit along with written instructions for correct teeth cleaning. Before the bonding of fixed appliances, none of the subjects had any periodontal disease, and oral hygiene was judged to be excellent (no plaque apposition). After 90 days of treatment, debris accumulation was present, mainly at retention places, while gingivitis was diagnosed sporadically.

From each of the 15 subjects included in the study - who were wearing a fixed appliance composed of 20 brackets, 4 tubes, and two archwires-one bracket, one NiTi, and one SS archwire were retrieved after 90 days of intraoral exposure. A semi-quantitative analysis of the debris deposited on the surface of each of the 15 brackets and 30 archwires (15 SS and $15 \mathrm{NiTi}$ ) was performed, using scanning electron microscopy (SEM; JOEL5500 LV, Tokyo, Japan) with energy-dispersive X-ray spectroscopy (EDS; Oxford Instruments, Abingdon, UK). The average content of metal ions and other elements in the debris on the surface of all analyzed brackets and archwires was assessed and expressed as mean values of weight percentages (wt.\%) for brackets, SS, and NiTi archwires, separately.

\subsection{Comparison of the In Vitro and In Vivo Metal Ion Release}

To assess the differences between the in vitro and in vivo metal ion release, the average content of metal ions released in artificial saliva was also expressed as weight percentages. Since, as expected, the composition of in vivo collected debris was complex due to intraoral exposure, in the controlled in vitro setting, there was a limited number of metal ions detected in artificial saliva; the amount of $\mathrm{Ni}$, which was present in all samples, was used as a reference for comparison. Briefly, the weight percentages of other metal ions were expressed in relation to the weight percentage of $\mathrm{Ni}$ (as a multiplier) within each setting. Of note, the comparison was performed for metal ions detected in the in vitro setting ( $\mathrm{Fe}$, $\mathrm{Cr}, \mathrm{Ti}, \mathrm{Mb})$.

\section{Results}

The metal compositions of each sample derived by ICP-MS evidenced that brackets and archwires that were, according to the manufacturer declaration, made of stainless steel had roughly the same composition. The Fe content was $55.4 \mathrm{wt} . \%$ and $58.3 \mathrm{wt} . \%$, while the Cr content was 24.9 wt.\% and $27.1 \mathrm{wt} . \%$, respectively, for SS brackets and SS archwires. Ni content was $17.8 \mathrm{wt} . \%$ in brackets and $14.6 \mathrm{wt} . \%$ in SS archwires, whereas Ti and Co were found in less than $0.1 \mathrm{wt} . \%$ for both brackets and SS archwires. As for Mo, its content was $1.95 \mathrm{wt} . \%$ in brackets and less than $0.1 \mathrm{wt} . \%$ in SS archwires. The NiTi archwire was mainly 
composed of $\mathrm{Ni}(73.2 \mathrm{wt} . \%)$ and $\mathrm{Ti}(26.8 \mathrm{wt} . \%)$, with other elements (Fe, $\mathrm{Cr}, \mathrm{Co}$, and $\mathrm{Mo}$ ) in quantities lower than $0.1 \mathrm{wt} . \%$.

Fe release was dominant over the other metals for both SS brackets and archwires among the released metal ions from orthodontic appliances into artificial saliva after 90 days of exposure. However, higher concentrations were detected in the brackets' sample $\left(\mathrm{Fe} \approx 3209 \mathrm{ng} / \mathrm{cm}^{2}\right)$ than the SS archwires' sample $\left(\mathrm{Fe} \approx 607 \mathrm{ng} / \mathrm{cm}^{2}\right)$. Similarly, the concentrations of $\mathrm{Ni}$ and $\mathrm{Cr}$ after 90 days of exposure were higher for the brackets' sample (593 ng/ $\mathrm{cm}^{2}$ and $111 \mathrm{ng} / \mathrm{cm}^{2}$, for $\mathrm{Ni}$ and $\mathrm{Cr}$, respectively) compared with the SS archwire sample ( $96 \mathrm{ng} / \mathrm{cm}^{2}$ and $26 \mathrm{ng} / \mathrm{cm}^{2}$, for $\mathrm{Ni}$ and $\mathrm{Cr}$, respectively). Of note, in the case of the brackets' sample, Mo was also detected $\left(\mathrm{Mo} \approx 29 \mathrm{ng} / \mathrm{cm}^{2}\right)$. Regarding the NiTi archwires, both $\mathrm{Ni}$ and $\mathrm{Ti}$ were released, reaching after 90 days of exposure a concentration of $\approx 781 \mathrm{ng} / \mathrm{cm}^{2}$ and $\approx 577 \mathrm{ng} / \mathrm{cm}^{2}$ for $\mathrm{Ni}$ and $\mathrm{Ti}$, respectively. The metal ions content (wt.\%) in either artificial saliva or debris on the surface of brackets and archwires after 90 days of exposure is presented in Figure $1 \mathrm{a}-\mathrm{c}$ for the in vitro and Figure $1 \mathrm{~d}-\mathrm{f}$ for the in vivo setting.

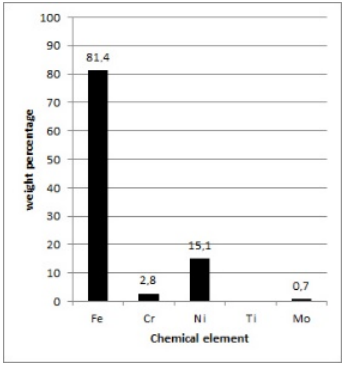

(a)

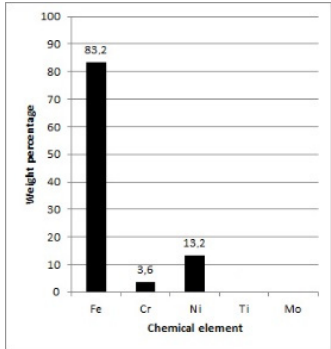

(b)

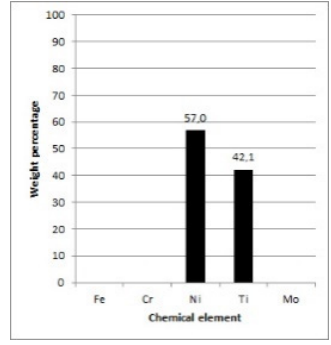

(c)

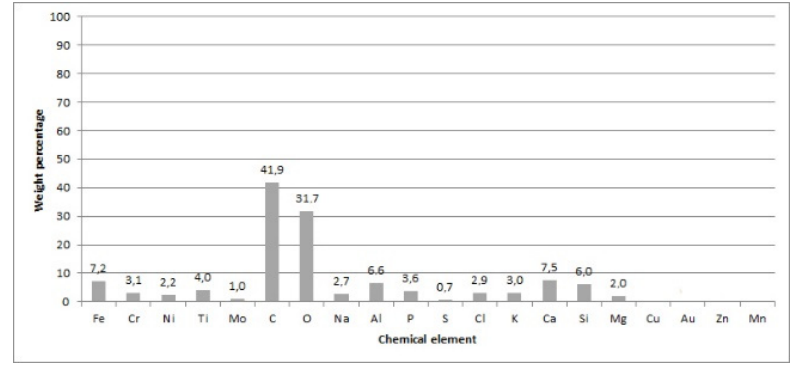

(d)

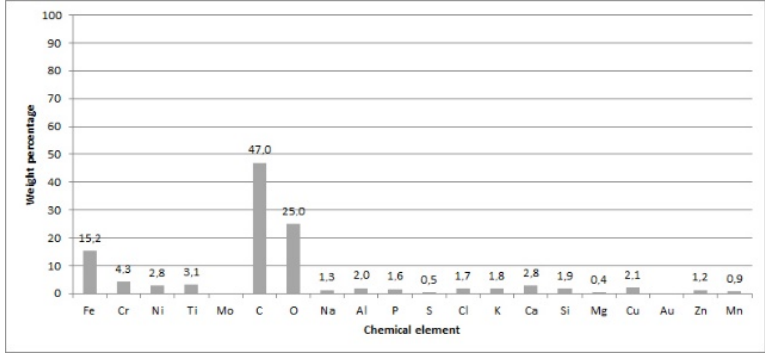

(e)

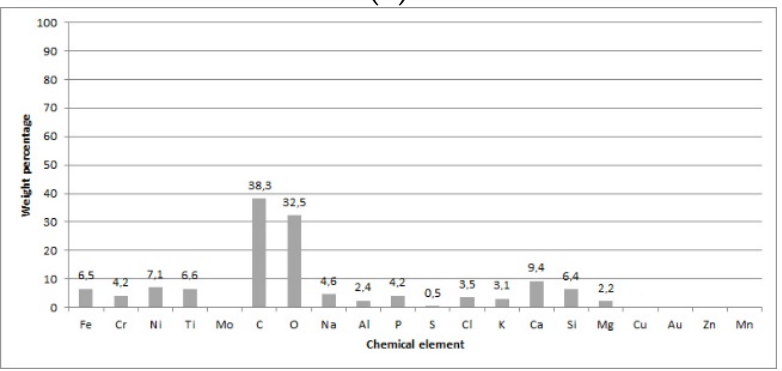

$(\mathbf{f})$

Figure 1. Weight percentages of elements released from: (a,d) SS brackets, (b,e) SS archwires, and (c,f) $\mathrm{NiTi}$ archwires either for the $(\mathbf{a}-\mathbf{c})$ in vitro or $(\mathbf{d}-\mathbf{f})$ in vivo setting. Note that for the in vivo setting, average percentages among the 15 patients included are reported.

After 90-days of in vitro exposure (Figure 1a-c), only metal ions could be detected in artificial saliva; in vivo exposure of brackets and archwires (Figure $1 \mathrm{~d}-\mathrm{f}$ ) evidenced a high content of $\mathrm{C}$ and $\mathrm{O}$, regardless of the type of surface material (SS or NiTi). Moreover, $\mathrm{Ca}, \mathrm{P}$, $\mathrm{Na}, \mathrm{K}$, and $\mathrm{Cl}$ deposits were also detected. Regarding metal ions, $\mathrm{Fe}, \mathrm{Cr}, \mathrm{Ni}$, and $\mathrm{Ti}$ were the most prevalent on both brackets and archwires. The highest content of Fe was detected 
on the SS archwire's surface (Figure 1e; 15.2 wt.\%). Similar wt.\% of $\mathrm{Cr}$ was seen on all three types of surfaces, while the content of Ni was higher on NiTi archwires (Figure 2f; $7.1 \mathrm{wt} . \%$ ) compared with brackets and SS archwires (2.2 wt.\% and $2.8 \mathrm{wt} . \%$, respectively). Similarly, for Ti, a higher content was seen on NiTi archwires (6.6 wt.\%) than brackets (3.9 wt.\%) and SS archwires (Figure 1e; $3.1 \mathrm{wt} . \%$ ). Of note, traces of Mo were detected on brackets (1.0 wt.\%). Interestingly, for the in vivo exposed NiTi archwire, $\mathrm{Fe}$ and $\mathrm{Cr}$ were also seen on their surface, while in artificial saliva, no traces of these two metal ions could be detected.

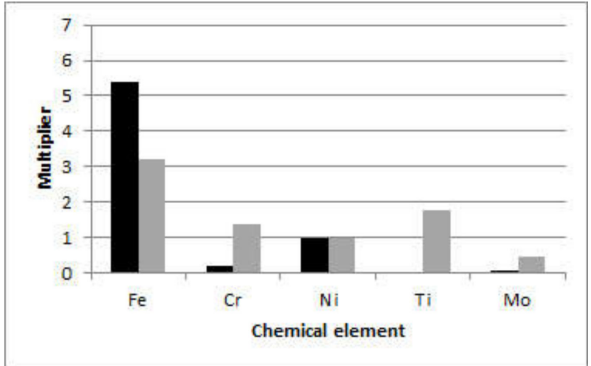

(a)

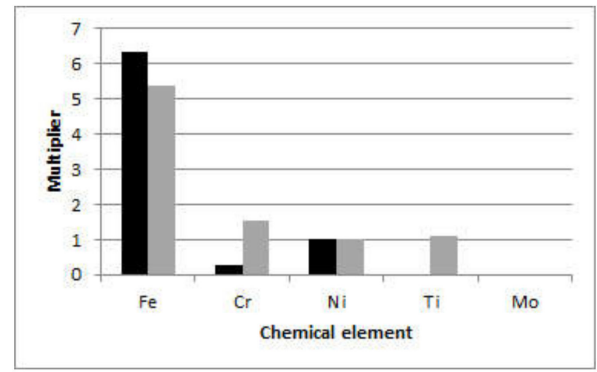

(b)

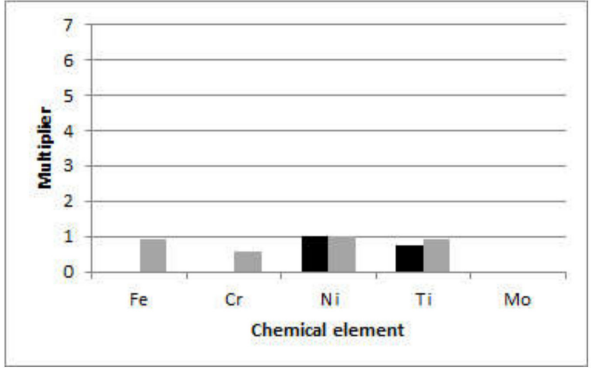

(c)

Figure 2. Content of different metal ions relative to $\mathrm{Ni}$ for the in vitro (black) and in vivo (gray) exposure of: (a) SS brackets, (b) SS archwires, and (c) NiTi archwires. The values on the $y$-axes represent the multipliers of the $\mathrm{Ni}$ wt.\% within each setting.

To compare the in vitro and in vivo results within each setting, the content of metal ions relative to the content of $\mathrm{Ni}$ (the only ion detected in all samples) was calculated and shown in Figure 2. For brackets (Figure 2a), the wt.\% of Fe was more than 3 times that of $\mathrm{Ni}$ for the in vitro and more than 5 times for the in vivo setting. The wt. $\%$ of $\mathrm{Cr}$ released in artificial saliva was approximately 0.2 that of $\mathrm{Ni}$, while for the in vivo setting, it was 1.4 times that of Ni. For SS archwires (Figure 2b), the wt.\% of Fe was more than 5 times that of $\mathrm{Ni}$ for both the in vitro (6.3 times that of $\mathrm{Ni}$ ) and in vivo (5.4 times that of $\mathrm{Ni}$ ) settings. The relative $\mathrm{Cr} w t . \%$ were higher for the in vivo (1.5 times that of $\mathrm{Ni}$ ) than for the in vitro ( 0.3 times that of $\mathrm{Ni}$ ) setting. On both SS brackets and SS archwires, Ti was detected after in vivo exposure, but it was not present in artificial saliva. Mo was detected in artificial saliva and debris of exposed SS brackets, with wt. $\% 9$ times higher on in vivo exposed brackets than artificial saliva; however, it was still below $0.5 \mathrm{wt} . \%$. Regarding the $\mathrm{NiTi}$ archwires, for the in vivo setting, Fe was detected in almost equal wt. $\%$ as $\mathrm{Ni}$, while $\mathrm{Cr} w t . \%$ was 0.6 that of Ni. Moreover, Ti wt.\% were slightly higher than those detected in artificial saliva.

\section{Discussion}

The present study evidenced a difference in the composition of released metal ions from fixed orthodontic appliances detected in an in vitro and in vivo setting. Although it has been claimed that constant saliva flow in the in vivo setting possibly dilutes the released metal ions $[5,14]$, the present study evidenced that metal ions locally accumulate in the debris on the surfaces of in vivo exposed brackets and archwires. Generally, the relative 
content of metal ions was higher in the retrieved debris than in that released in artificial saliva. The only exception was detected for $\mathrm{Fe}$, of which the relative content in the debris of SS brackets and archwires was slightly lower than that released into artificial saliva.

For the in vitro setting, metal ion release from brackets and archwires were measured separately and, in the case of archwires, also according to their material. This could be regarded as a study limitation since it excluded the possible corrosive effect and related ions released due to different materials interactions. The additional mechanical aspect of bracket and archwire friction was neglected in such a setting since mechanical wear can additionally contribute to the metal ions release [15]. To overcome this limitation, the metal content of the debris collected on the surface of orthodontics material exposed in the oral cavity for 90 days was also analyzed. Metal ions that were not present in artificial saliva of specific in vitro samples were present in the debris retrieved from the surface of in vivo-exposed orthodontic material. More in detail, Fe and $\mathrm{Cr}$ that were not released from NiTi archwires into artificial saliva were detected in the debris accumulated during intraoral exposure.

Moreover, in vivo results of the metal content analysis of debris deposited on brackets and archwires demonstrated that despite the constant saliva flow and wash-out, a higher content of $\mathrm{Cr}$ was detected on brackets, SS, and NiTi archwires. However, their extrapolated concentrations were lower than the upper daily intake limit. Interestingly, $\mathrm{Fe}$ and $\mathrm{Cr}$ were also detected on NiTi archwires, and Ti was detected on SS brackets and archwires in vivo, although these metal ions were detected only in negligible amounts in the in vitro setting. These metal ions in the debris could derive from food, toothpaste, or contact contamination of metal ions released from other materials present in the oral cavity and affected by corrosion and/or tribocorrosion processes.

Although the measured cumulative concentrations of specific metal ions released in artificial saliva over 90 days of exposure did not exceed the recommended dietary intake levels, the analysis of the metal ion content in the debris retrieved from the surface of orthodontic appliances showed that most of the metal ions analyzed had a relatively higher content. This could be explained by the ever-changing environmental conditions to which different orthodontic materials are subjected in the oral cavity. In particular, the fluctuating $\mathrm{pH}$ [16] and temperatures, as well as mechanical forces, might increase both electrochemical and tribocorrosion [15].

Fe ions were released in the artificial saliva in the highest concentrations from both SS brackets and archwires, compared with other potentially allergenic and cytotoxic ions (Ni and $\mathrm{Cr}$ ) found in them, which were released in at least 5 times lower concentrations than Fe. Interestingly, after comparing released ion concentrations for each orthodontic material with the alloys metal composition, it appears that there was no correlation. Stainless steel brackets, for example, contain $56 \mathrm{wt} . \%$ of $\mathrm{Fe}$, but the relative percentage of the released Fe metal ions was much higher than that at $80 \mathrm{wt} . \%$. A similarity with our findings was previously reported by Hwang et al. [17]. Moreover, Hussain et al. [18] concluded that the ion release is not dependent on the alloy ion amount but rather on the nature of the alloy and its manufacturing process. In vitro-detected Fe was almost twice that detected in vivo on brackets, while roughly similar amounts of Fe were seen on SS archwires after either in vitro or in vivo exposure.

On the contrary, $\mathrm{Cr}$ wt.\% were 7 and 5 times higher in the debris of in vivo-exposed SS brackets and SS archwires, respectively, than those detected in artificial saliva. Since corrosion is the main reason for ion release, the scale of it depends on the formation of passive oxide layers ( $\mathrm{Cr}$ oxide or Ti oxide) on the surfaces of orthodontic materials, which have a preventive role [19]. According to Pulikkottil et al. [20], stainless steel alloys containing at least $11 \mathrm{wt} . \% \mathrm{Cr}$ can form a passive oxide layer to protect against corrosion, thus limiting ion release. However, protective oxide layers, in addition to the surface metal composition, are also highly influenced by the changes in the oral environment, such as $\mathrm{pH}$ and temperature levels, as well as mechanical forces (i.e., friction upon sliding) causing tribocorrosion. Therefore, their disruption possibly increases $\mathrm{Cr}$ release in the oral cavity 
and its accumulation in the debris. In the present study, for the in vitro setting, a constant $\mathrm{pH}$ and temperature were kept, which avoided a potential increase in ion release [21] and could explain the higher content of $\mathrm{Cr}$ on in vivo-exposed brackets and archwires than those in the in vitro setting.

Interestingly, $\mathrm{Cr}$ was also detected on in vivo-exposed NiTi archwires, probably originating from adjacent materials or food. An upper intake limit has not yet been established for $\mathrm{Cr}$, but its recommended daily intake is $200 \mu \mathrm{g} /$ day [22]. Considering the cumulative $\mathrm{Cr}$ concentrations of the in vitro results, they did not exceed the prescribed daily intake concentrations. Moreover, a previous study on salivary $\mathrm{Cr}$ secretion in patients with fixed orthodontic appliances reported similar salivary $\mathrm{Cr}$ levels in treated and untreated subjects [23]. However, this sense of safety may be false due to non-toxic systemic concentrations of metals inducing biological effects to the adjacent oral tissues [10] due to their local accumulation in the debris.

$\mathrm{Ni}$ was released in 6 times higher concentrations from NiTi archwires than SS archwires, an effect also observed by Senkutvan et al. [24] and Hussain et al. [18], where the Ni release of NiTi archwire was $4.85 \mathrm{ppb}$ compared with SS archwire's $0.41 \mathrm{ppb}$ ion release. Hwang et al. [17] reported similar results as ours regarding the concentrations of $\mathrm{Ni}$ ions released from NiTi archwires, while Mikulewicz et al. [25] reported that an orthodontic appliance made of stainless steel after 30 days immersion in artificial saliva leached $573 \mathrm{ng} / \mathrm{mL}$ of Ni. The higher values evidenced by Mikulewicz et al. [25] could be due to their specific study design that included constant shaking of the samples at $120 \mathrm{rpm}$ over 30 days (simulating somehow additional mechanical forces). In contrast, samples were slightly shaken in our study, though the in vitro results measured metal ions released mainly due to electrochemical corrosion. Although it was impossible to assess whether the $\mathrm{Ni}$ content was higher in the accumulated debris, it is plausible to assume that mechanical wear in the oral cavity increased $\mathrm{Ni}$ release from in vivo-exposed orthodontic material. It has been previously demonstrated that Ni salivary secretion among subjects undergoing treatment with fixed orthodontic appliances was significantly higher than that of control subjects [23]. According to the reported upper intake limits, the highest dietary intake level for $\mathrm{Ni}$ that imposes no threat is $1 \mathrm{mg} /$ day [22]. Based on the results of the present and previous studies, it is hard to believe that this level could be reached by (tribo)corrosion of orthodontic materials. However, due to the possible Ni ion accumulation in higher concentrations in the debris, hypersensitivity reactions of local tissues cannot be excluded as an adverse effect even at lower leached concentrations [26].

Although Ti content in the analyzed material (SS brackets and SS archwires) was below $0.1 \mathrm{wt} . \%$, Ti was detected on both in vivo-exposed SS brackets and SS archwires. The observed Ti in the debris on SS brackets and archwires could be a deposit either from food (e.g., titanium dioxide used as a food additive (E171) to enhance and brighten the color of white foods) or toothpaste or from NiTi archwires in the case of brackets due to archwire sliding along the bracket. In fact, Ti constitutes the protective oxide layer $\left(\mathrm{TiO}_{2}\right)$ present on the surface of NiTi archwires [27] that is subjected to disruption due to mechanical forces during sliding. The upper intake limit for Ti is $1.1 \mathrm{mg} /$ day [22], and it was not reached based on the measurements of the in vitro setting. Even though the Ti content in the debris was higher than that detected in artificial saliva, its local adverse effects are negligible due to its well-known biocompatibility.

In the case of brackets, very low concentrations of Mo were released in artificial saliva. Mo was also detected in the debris of in vivo-exposed brackets, with wt.\% 9 times greater than those in artificial saliva, but still clinically negligible amounts. Interestingly, Mo was not released from SS archwires, either in vitro or in vivo. Therefore, even though we might be dealing with the same type of alloy (SS), its composition can be different among manufacturers. In fact, ICP-MS analysis confirmed that the wt.\% of Mo in brackets was almost $2 \%$, while in SS archwires the wt. $\%$ was less than $0.1 \%$.

It appears that the in vitro setting of the present study slightly underestimated the metal ions released from orthodontic material, probably since combinations of different 
alloys, which might lead to higher total ions release and, therefore, to potential synergistic harmful effects, were not considered. Additionally, tribocorrosion and other frequent oral cavity changes could hardly be simulated in an in vitro setting. Moreover, for the in vitro setting, we aimed to assess the concentrations of the five most common metal ions present in alloys of orthodontic appliances. Therefore, it cannot be excluded that other metal ions were also released from the samples during exposure, as seen in the in vivo analysis. However, other elements detected in the debris could also derive from food and beverage intake. In fact, several other elements in traces were seen for the in vivo setting in addition to the organic part. On the other hand, by performing multi-element analysis with the ICP-MS, we were able to determine precisely which part of the orthodontic appliance accounted for the greatest ions release compared with the others and its release profile characteristic during the 90-day study. Moreover, the use of Teflon beakers as vessels for orthodontic material submersion prevented any possible metal ion adsorption to the beaker surface and allowed for a constant $\mathrm{pH}$ level throughout the study.

The risk assessment process, from which an upper recommended daily limit is obtained for an individual metal, is not an appropriate tool for the "cocktail scenario" assessment exposure, as it does not consider different combinations of metals and their synergistic effects. Additionally, if the metal ion daily dose derived from all parts of an orthodontic appliance and from daily diets are added up, a higher dose could be reached. However, the present in vivo setting results show that although higher, these levels are still below the upper daily intake limit. Nevertheless, local cytotoxic effects and oxidative tissue damage could not be excluded. Previous reports confirm that metal ions released from fixed orthodontic appliances could damage oxidative stress observed at the cellular level [28]. Therefore, from a clinical standpoint, the long term increasing accumulation of metal ions in the debris might cause, if not removed, possible local adverse effects, stressing even more the importance of excellent oral hygiene throughout treatment. On the other hand, the balance between individual tissue susceptibility and endogenous defense mechanisms may also play a role in causing or preventing deleterious effects to (oral) health.

\section{Conclusions}

Knowing the metal composition of orthodontic appliances and orthodontic alloys and corrosiveness and metal ion release into the oral environment provides necessary information with which an orthodontist may consider the possible harmful local or systemic effects of an appliance. When comparing metal ion release from different orthodontic alloys during 90 days of exposure in artificial saliva, the concentrations of released metal ions from all tested alloys were below the upper recommended limit of daily intake. However, the amount of metal ions accumulated in the debris collected from the surface of different parts of orthodontic appliances after intraoral aging was higher than that in artificial saliva. Therefore, when testing new orthodontic material for intraoral use, an in vivo setting should also be taken into account due to the underestimation of metal ion release evidenced by the present study when using only the in vitro setting.

Author Contributions: All authors discussed and agreed upon the idea and made scientific contributions: writing-original draft preparation J.P. and V.K.; experiment designing, V.K. and B.P.; performing the in vitro experiment, V.K. and M.B.; performing the in vivo experiment, U.M.; analyzing data, V.K., M.B., J.P. and J.S.; writing-review and editing, V.K., B.P., J.S., U.M. and J.P.; supervising, B.P. and J.P. All authors have read and agreed to the published version of the manuscript.

Funding: This research was funded by the Slovenian Research Agency (Grant Nos. P3-0388, P1-0143, J3-2523, and J3-2520).

Institutional Review Board Statement: The study was conducted in accordance with the Declaration of Helsinki, and the study was approved by the Medical Ethics Committee of the Republic of Slovenia (protocol code 126/04/13, 20 May 2013).

Informed Consent Statement: Informed consent was obtained from all subjects involved in the study. 
Data Availability Statement: The data underlying this article will be shared on reasonable request to the corresponding author.

Acknowledgments: We would like to acknowledge Radmila Milačič for organizing this collaboration.

Conflicts of Interest: The authors declare no conflict of interest. The funders had no role in the design of the study; in the collection, analyses, or interpretation of data; in the writing of the manuscript; or in the decision to publish the results.

\section{References}

1. Barrett, R.D.; Bishara, S.E.; Quinn, J.K. Biodegradation of orthodontic appliances. Part I. Biodegradation of nickel and chromium in vitro. Am. J. Orthod. Dentofac. Orthop. 1993, 103, 8-14. [CrossRef]

2. Mocnik, P.; Kosec, T.; Kovac, J.; Bizjak, M. The effect of pH, fluoride and tribocorrosion on the surface properties of dental archwires. Mater. Sci. Eng. C Mater. Biol. Appl. 2017, 78, 682-689. [CrossRef] [PubMed]

3. Keinan, D.; Mass, E.; Zilberman, U. Absorption of nickel, chromium, and iron by the root surface of primary molars covered with stainless steel crowns. Int. J. Dent. 2010, 2010, 326124. [CrossRef] [PubMed]

4. Mikulewicz, M.; Chojnacka, K. Release of metal ions from orthodontic appliances by in vitro studies: A systematic literature review. Biol. Trace Elem. Res. 2011, 139, 241-256. [CrossRef] [PubMed]

5. Mikulewicz, M.; Chojnacka, K.; Wolowiec, P. Release of metal ions from fixed orthodontic appliance: An in vitro study in continuous flow system. Angle Orthod. 2014, 84, 140-148. [CrossRef] [PubMed]

6. Pantuzo, M.C.; Zenobio, E.G.; de Andrade Marigo, H.; Zenobio, M.A. Hypersensitivity to conventional and to nickel-free orthodontic brackets. Braz. Oral. Res. 2007, 21, 298-302. [CrossRef]

7. Sifakakis, I.; Eliades, T. Adverse reactions to orthodontic materials. Aust. Dent. J. 2017, 62, 20-28. [CrossRef]

8. Lindsten, R.; Kurol, J. Orthodontic appliances in relation to nickel hypersensitivity. A review. J. Orofac. Orthop. 1997, 58, 100-108.

9. Ortiz, A.J.; Fernandez, E.; Vicente, A.; Calvo, J.L.; Ortiz, C. Metallic ions released from stainless steel, nickel-free, and titanium orthodontic alloys: Toxicity and DNA damage. Am. J. Orthod. Dentofac. Orthop. 2011, 140, e115-e122. [CrossRef]

10. Faccioni, F.; Franceschetti, P.; Cerpelloni, M.; Fracasso, M.E. In vivo study on metal release from fixed orthodontic appliances and DNA damage in oral mucosa cells. Am. J. Orthod. Dentofac. Orthop. 2003, 124, 687-693. [CrossRef]

11. Eliades, T.; Athanasiou, A.E. In vivo aging of orthodontic alloys: Implications for corrosion potential, nickel release, and biocompatibility. Angle Orthod. 2002, 72, 222-237. [PubMed]

12. Kosec, T.; Močnik, P.; Mezeg, U.; Legat, A.; Ovsenik, M.; Jenko, M.; Grant, J.T.; Primožič, J. Tribocorrosive study of new and in vivo exposed nickel titanium and stainless steel orthodontic archwires. Coatings 2020, 10, 230. [CrossRef]

13. Kovac, V.; Bergant, M.; Scancar, J.; Primozic, J.; Jamnik, P.; Poljsak, B. Causation of Oxidative Stress and Defense Response of a Yeast Cell Model after Treatment with Orthodontic Alloys Consisting of Metal Ions. Antioxidants 2021, 11, 63. [CrossRef] [PubMed]

14. Dwivedi, A.; Tikku, T.; Khanna, R.; Maurya, R.P.; Verma, G.; Murthy, R.C. Release of nickel and chromium ions in the saliva of patients with fixed orthodontic appliance: An in-vivo study. Natl. J. Maxillofac. Surg. 2015, 6, 62-66. [CrossRef]

15. Staffolani, N.; Damiani, F.; Lilli, C.; Guerra, M.; Staffolani, N.J.; Belcastro, S.; Locci, P. Ion release from orthodontic appliances. J. Dent. 1999, 27, 449-454. [CrossRef]

16. Galeotti, A.; Uomo, R.; Spagnuolo, G.; Paduano, S.; Cimino, R.; Valletta, R.; D’Anto, V. Effect of pH on in vitro biocompatibility of orthodontic miniscrew implants. Prog. Orthod. 2013, 14, 15. [CrossRef]

17. Hwang, C.J.; Shin, J.S.; Cha, J.Y. Metal release from simulated fixed orthodontic appliances. Am. J. Orthod. Dentofac. Orthop. 2001, 120, 383-391. [CrossRef]

18. Hussain, H.D.; Ajith, S.D.; Goel, P. Nickel release from stainless steel and nickel titanium archwires-An in vitro study. J. Oral. Biol. Craniofac. Res. 2016, 6, 213-218. [CrossRef]

19. Eliades, T.; Pratsinis, H.; Kletsas, D.; Eliades, G.; Makou, M. Characterization and cytotoxicity of ions released from stainless steel and nickel-titanium orthodontic alloys. Am. J. Orthod. Dentofac. Orthop. 2004, 125, 24-29. [CrossRef]

20. Pulikkottil, V.J.; Chidambaram, S.; Bejoy, P.U.; Femin, P.K.; Paul, P.; Rishad, M. Corrosion resistance of stainless steel, nickeltitanium, titanium molybdenum alloy, and ion-implanted titanium molybdenum alloy archwires in acidic fluoride-containing artificial saliva: An in vitro study. J. Pharm. Bioallied Sci. 2016, 8, S96-S99.

21. Kuhta, M.; Pavlin, D.; Slaj, M.; Varga, S.; Lapter-Varga, M.; Slaj, M. Type of archwire and level of acidity: Effects on the release of metal ions from orthodontic appliances. Angle Orthod. 2009, 79, 102-110. [CrossRef] [PubMed]

22. Trumbo, P.; Yates, A.A.; Schlicker, S.; Poos, M. Dietary reference intakes: Vitamin A, vitamin K, arsenic, boron, chromium, copper, iodine, iron, manganese, molybdenum, nickel, silicon, vanadium, and zinc. J. Am. Diet. Assoc. 2001, 101, 294-301. [CrossRef]

23. Amini, F.; Jafari, A.; Amini, P.; Sepasi, S. Metal ion release from fixed orthodontic appliances-An in vivo study. Eur. J. Orthod. 2012, 34, 126-130. [CrossRef]

24. Senkutvan, R.S.; Jacob, S.; Charles, A.; Vadgaonkar, V.; Jatol-Tekade, S.; Gangurde, P. Evaluation of nickel ion release from various orthodontic arch wires: An in vitro study. J. Int. Soc. Prev. Community Dent. 2014, 4, 12-16.

25. Mikulewicz, M.; Chojnacka, K.; Wozniak, B.; Downarowicz, P. Release of metal ions from orthodontic appliances: An in vitro study. Biol. Trace Elem. Res. 2012, 146, 272-280. [CrossRef] 
26. Genelhu, M.C.; Marigo, M.; Alves-Oliveira, L.F.; Malaquias, L.C.; Gomez, R.S. Characterization of nickel-induced allergic contact stomatitis associated with fixed orthodontic appliances. Am. J. Orthod. Dentofac. Orthop. 2005, 128, 378-381. [CrossRef] [PubMed]

27. Ramazanzadeh, B.A.; Ahrari, F.; Sabzevari, B.; Habibi, S. Nickel Ion Release from Three Types of Nickel-titanium-based Orthodontic Archwires in the As-received State and After Oral Simulation. J. Dent. Res. Dent. Clin. Dent. Prospect. 2014, 8, 71-76.

28. Kovac, V.; Poljsak, B.; Primozic, J.; Jamnik, P. Are Metal Ions That Make up Orthodontic Alloys Cytotoxic, and Do They Induce Oxidative Stress in a Yeast Cell Model? Int. J. Mol. Sci. 2020, 21, 7993. [CrossRef] 